\title{
Regulation of Human Heart Contractility by Essential Myosin Light Chain Isoforms
}

\author{
Marija Morano, ${ }^{\star}$ Udo Zacharzowski, ${ }^{*}$ Michaela Maier, ${ }^{\ddagger}$ Peter E. Lange,, Vladimir Alexi-Meskishvili, ${ }^{\ddagger}$ Hannelore Haase, ${ }^{\star}$ \\ and Ingo Morano* \\ *Max-Delbrück-Center for Molecular Medicine, 13122 Berlin, Germany; and ${ }^{\ddagger}$ German Heart Center, Berlin, Germany
}

\begin{abstract}
Most of the patients with congenital heart diseases express the atrial myosin light chain 1 (ALC-1) in the right ventricle. We investigated the functional consequences of ALC-1 expression on the myosin cycling kinetics in the intact sarcomeric structure using multicellular demembranated fibers ("skinned fibers") from the right ventricular infundibulum of patients with Tetralogy of Fallot (TOF), double outlet right ventricle (DORV), and infundibular pulmonary stenosis (IPS). Force-velocity relation was analyzed by the constant-load technique at maximal $\mathrm{Ca}^{2+}$ activation (pCa 4.5). Half-time of tension develoment $\left(t_{1 / 2}\right)$ was investigated by monitoring contraction initiation upon photolytic release of ATP from caged-ATP in rigor. The patients investigated here expressed between 0 and 27\% ALC-1. There was a statistically significant correlation between ALC-1 and maximal shortening velocity $\left(V_{\max }\right)$ which rose 1.87-fold from 1.2 muscle length per second (ML/s) to $2.25 \mathrm{ML} / \mathrm{s}$ in a normal (0\% ALC-1) and diseased (19.9\% ALC-1) ventricle. Halftime of tension development decreased 1.85 -fold with increasing ALC-1 expression ( $t_{1 / 2}$ was $0.252 \mathrm{~s}$ and $0.136 \mathrm{~s}$ at 2 and $18.4 \%$ ALC-1, respectively). We conclude that the expression of ALC-1 in the human heart modulates crossbridge cycling kinetics accelerating shortening velocity and isometric tension production. (J. Clin. Invest. 1996. 98:467473.) Key words: myosin light chains • human heart • cardiac contractility $\bullet$ congenital heart disease - Tetralogy of Fallot
\end{abstract}

\section{Introduction}

The type II myosin molecule of the heart is a hexamer consisting of two heavy chains (MHC; ${ }^{1} 200 \mathrm{kD}$ ) each associated with light chains (MLC; 18-28 kD). Two cardiac-specific genes coding for $\mathrm{MHC}$ are expressed, namely the $\alpha$-MHC and the

Address correspondence to Dr. Ingo Morano, Max-Delbrück-Center for Molecular Medicine, Robert-Rössle-Straße 10, 13122 Berlin, Germany. Phone: 49309406 2313; FAX: 493094062277.

Received for publication 12 February 1996 and accepted in revised form 9 May 1996.

1. Abbreviations used in this paper: A, actin; ALC, atrial light chain; BDM, 2,3-butanedione monoxime; DORV, double-outlet light ventricle; IPS, infundibular pulmonary stenosis; M, myosin; MHC, myosin heavy chain; MLC, myosin light chain; TOF, Tetralogy of Fallot; 2D, two-dimensional; VLC, ventricular light chain.

J. Clin. Invest.

(C) The American Society for Clinical Investigation, Inc.

0021-9738/96/07/0467/07 \$2.00

Volume 98, Number 2, July 1996, 467-473
$\beta$-MHC located in tandem on chromosome 14 (2-4). The MLC types are classified into essential MLC (or MLC-1) and regulatory (phosphorylatable) MLC (or MLC-2) $(5,6)$. Recent $\mathrm{X}$-ray crystallographic analysis demonstrated that both essential and regulatory MLC are associated with the neck region of the myosin-S1 fragment (7). In the human heart, five different MLC isoforms exist which are expressed in a tissue-specific manner: there are three regulatory (phosphorylatable) myosin light chains, namely two ventricular-specific (VLC-2 and VLC$2 *)$ and an atrial-specific (ALC-2) $(8,9)$. The ventricular regulatory light chains are monophosphorlyated each, while the ALC-2 may be mono- and diphosphorylated (9). Two essential myosin light chain isoforms are produced by two different genes, namely a VLC-1 which is the same isoform as the MLC-1s present in adult slow skeletal muscle, and an atrial-specific (ALC-1) isoform (10). Two different ALC-1 transcripts have been described on the mRNA level which differed in their $5^{\prime}$ and $3^{\prime}$ - untranslated regions having identical protein coding sequences (11). In the murine, two E boxes (which interact with muscle-specific regulatory proteins of the MyoD family) and a diverged CArG box (which binds the serum response factor) exist within the first $630 \mathrm{bp}$ of the ALC-1 promoter region (12). E boxes have been shown to be sufficient for ALC-1 transcription regulation during skeletal muscle differentiation (12). Human embryos express large amounts of ALC-1 in the whole heart and in skeletal muscle (8). Therefore, the ALC-1 was designated as the embryonic MLC (MLC-1emb) (for review see 13). ALC-1 expression in the ventricle decreases to undetectable levels during early postnatal development but persists in the atrium for the whole life $(8,14,15)$. The situation is different in patients with congenital heart disease, e.g., with Tetralogy of Fallot (TOF), double-outlet right ventricle (DORV), and infundibular pulmonary stenosis (IPS). TOF is a complex congenital heart disease characterized by four components: a right ventricular infundibular stenosis, a ventricular septal defect, a dextroposed aorta overriding the interventricular septal defect, and right ventricular hypertrophy (16). DORV is considered as a partial transposition complex in which both great arteries arise from the right ventricle. Our patients were from the "Fallot-type" (infundibular stenosis, ventricular septal defect, right ventricular hypertrophy). IPS is a pulmonary infundibular stenosis narrowing the right ventricular outflow tract associated with hypertrophy of the right ventricle. The hypertrophied right ventricle of children with TOF expresses large amounts of ALC-1 in the ventricle up to adulthood (14). Similarly, the hypertrophied left ventricle of patients with ischaemic or dilative cardiomyopathy reexpresses ALC-1 (17). Surgical intervention with subsequent normalization of the hemodynamic state decreases ALC-1 expression in these patients (18).

However, the physiological role of the essential light chains is still not well characterized. To selectively analyze the physiological function of essential MLC in the human heart, we 
studied cross-bridge reaction in demembranated multicellular heart preparations ("skinned fibers") from right ventricular heart tissue of patients with different congenital heart diseases (TOF, DORV, IPS). These tissue specimens are of special interest since they contain myosin cross-bridges which differ only by their essential MLC isoforms having the subunit compositions: $\beta$-MHC, ALC-1, VLC-1, VLC-2, and VLC-2*. Normal ventricular myosin consists of $\beta$-MHC, VLC-1, VLC-2, and VLC-2*. Therefore, we obtained the opportunity to selectively analyze the role of essential MLC on myosin crossbridge cycling and cardiac contractility. The rationale to use demembranated fibers for analysis of cross-bridge cycling kinetics is supported by a recent report which demonstrated that cross-bridge cycling in skinned and intact cardiac tissue is the same (29). To define cross-bridge cycling kinetics, we determined the maximal shortening velocity $\left(V_{\max }\right)$ as well as halftime of tension development $\left(t_{1 / 2}\right)$ of skinned fibers. The same preparations were used to analyze ALC-1 expression on the protein level.

In the intact contractile structure, the myosin cross-bridge (M) reaction is assumed to comprise complex interactions with actin (A) coupled with the hydrolysis of ATP to ADP and Pi. Myosin undergoes changes of its affinity during the cycle being strongly attached to actin (having high actin affinity) or weakly attached (having low actin affinity) $(30,31)$. Force production is considered to be associated with the Pi release step and the transition from weakly (nonforce generating) to strongly attached (force generating) states (cf. 32). Isotonic shortening, however is suggested to be rate limited by cross-bridge detachment and the ADP release (33).

Velocity of muscle shortening was analyzed by applying quick releases during isometric steady state tension under constant load conditions. To exclude the influence of changes in the expression of regulatory proteins on cross-bridge cycling, we activated the fibers with maximal free $\mathrm{Ca}^{2+}$ concentration (pCa 4.5). We determined the half-time of the transition from nonforce into force generating states by monitoring the force production upon photolytical release of ATP from caged-ATP in a low-tension rigor state in the presence of maximally activating $\mathrm{Ca}^{2+}$ concentration (cf. 21). Low-tension rigor is obtained by the presence of 2,3-butanedione monoxime (BDM) in the rigor solution. BDM binds to the myosin cross-bridges and inhibits the transition into force-generating states. Following the light flash, ATP is released and binds to myosin which is in the rigor (AM state). The cross-bridges detach from the rigor thus accumulating the myosin cross-bridges in nonforce generating states. Subsequently, they reattach and produce force due to the presence of high $\mathrm{Ca}^{2+}$. ATP release from caged ATP as well as detachment of cross-bridges from rigor are very rapid processes being $200 \mathrm{~s}^{-1}(34)$ and $4 \times 10^{4} \mathrm{M}^{-1} \mathrm{~s}^{-1}$ (35), respectively. Thus, we consider the tension development to be the rate-limiting reaction.

Here we describe for the first time that ventricular fibers with high amounts of ALC- 1 revealed a higher $V_{\max }$ and lower $t_{1 / 2}$ than fibers with no or low amounts of ALC- 1 . These results suggest that ALC-1 increases cycling kinetics of cardiac crossbridges thus regulating the contractile state of the heart.

\section{Materials and Methods}

Patient populations. Right ventricular infundibular tissue was obtained from 26 patients undergoing repair of congenital heart disease in the German Heart Center (Berlin, Germany): five patients with DORV, six patients with IPS, and 15 patients with TOF. Normal right ventricular tissue was obtained from a 10 -yr-old girl suffering from a parasite infection. All samples were immediately chemically skinned after resection. Hemodynamic data for all patients were available from preoperative right heart catheterization. Informed consent was obtained from all patients according to the local Ethical Committee.

Tissue preparation. All biochemical as well as mechanical experiments were performed with demembranated multicellular heart fibers (skinned fibers) prepared as described previously (19). In short, ventricular fiber bundles (about 1-mm thick, 1-6-mm long) were incubated in a solution containing $20 \mathrm{mM}$ imidazole, $10 \mathrm{mM} \mathrm{NaN}_{3}$, $5 \mathrm{mM}$ ATP, $5 \mathrm{mM} \mathrm{MgCl}$, $4 \mathrm{mM}$ EGTA, $2 \mathrm{mM}$ DTE, $50 \%$ glycerol, $1 \%$ Triton $\mathrm{x}-100, \mathrm{pH} 7$, at $4^{\circ} \mathrm{C}$ for $18-20 \mathrm{~h}$. Subsequently, the fibers were transferred into the same solution but without Triton X-100 and stored at $-20^{\circ} \mathrm{C}$.

Biochemical analysis. To obtain a direct correlation and to prevent the influence of possible regional inhomogeneities of ALC-1 expression, myosin light chains of the same skinned fiber previously mechanically investigated were analyzed by a high-resolution twodimensional gel electrophoresis (2D PAGE) technique. Isoelectric focussing (first dimension) was performed in glass capillaries (12.5$\mathrm{cm}$ long, 1-mm inner diameter) using the $\mathrm{pH}$ gradient 4.5-5.4 (pharmalytes; Pharmacia, Sweden). The gels were run overnight at $600 \mathrm{~V}$ constant for the first dimensional separation. The second dimension was a SDS-electrophoresis, using slab gels $10.5 \times 9.5 \mathrm{~cm}, 1$-mm thick. The gels were stained with Coomassie blue and the MLC were evaluated by computer-assisted scanner densitometry (ScanPack; Biometra, Germany).

Mechanical analysis. For all mechanical experiments, fibers were dissected into bundles of 150-200- $\mu \mathrm{m}$ diam and 3-6-mm long under a preparation microscope. Fibers were mounted isometrically between a force transducer and a length step generator with micro syringes in relaxation solution. Length was adjusted such that resting tension was threshold, using a micrometer screw. Sarcomere length at resting tension was always between 1.95 and $2.0 \mu \mathrm{m}$ as detected by laser diffraction analysis. Relaxation solution contained (mM): Imidazol (25), ATP (10), creatinphosphate (10), $\mathrm{MgCl}_{2}$ (12.5), $\mathrm{NaN}_{3}$ (5), DTE (1), EGTA (5), $\mathrm{KCl}$ (12.5), creatine kinase $380 \mathrm{U} / \mathrm{ml}, \mathrm{pH}$ 7. Contraction solution was the same as relaxation solution except that EGTA was substituted by $5 \mathrm{mM}$ CaEGTA. $\mathrm{Ca}^{2+}$-free rigor solution contained: $2.5 \mathrm{mM} \mathrm{MgCl}$, $5 \mathrm{mM}$ EGTA, $2 \mathrm{mM}$ DTE, BDM (100 mM), pH 7. $\mathrm{Ca}^{2+}$-rigor contained: $2.5 \mathrm{mM} \mathrm{MgCl}, 5 \mathrm{mM}$ CaEGTA, $2 \mathrm{mM}$ DTE, $\mathrm{pH}$ 7. Photolysis solution was made by adding $5 \mathrm{mM} P_{3}$-1-(2-nitrophenyl)-ethyladenosine-5'-triphosphate (caged-ATP; CalbiochemBehring Corp., San Diego, CA) and $10 \mathrm{mM}$ DTE to the $\mathrm{Ca}^{2+}$-rigor solution. Ionic strength was adjusted with $\mathrm{KCl}$ to $130 \mathrm{mM}$. Free $\mathrm{Ca}^{2+}$ concentrations were calculated according to a commercially available computer program (36).

Force-velocity measurements. The fibers were transfered from relaxation ( $\mathrm{pCa} 8$ ) into maximally $\mathrm{Ca}^{2+}$ activation solution (pCa 4.5). Force-velocity relations were determined by isotonic quick releases under constant load at $21^{\circ} \mathrm{C}$ using a commercially available setup (Scientific Instruments, Heidelberg, Germany). Load clamping for isotonic shortening was achieved by changing the mode of operation from length control to force control during isometric steady state tension. The force during isotonic contraction was held constant by the controlled motion of the length step generator, which followed the contracting fiber with the appropriate velocity. The force control mode was maintained for $250 \mathrm{~ms}$. The velocity of the length step was determined with an optoelectronical position detector. Both force and velocity signals were displayed on a storage digital oscilloscope (HM 408) and analyzed with an IBM compatible PC using the Proscope Hameg Software SP91. Velocity was measured between 20 and $50 \mathrm{~ms}$ after the onset of the quick release.

The relation between shortening velocity and force during isotonic contraction was analyzed using a linearized form of the Hill 1938 (37) equation: 
Table I.

\begin{tabular}{|c|c|c|c|c|c|c|}
\hline $\begin{array}{l}\text { Patient } \\
\text { number }\end{array}$ & Age & Diagnosis & Sex & ALC-1 $1 \pm$ SEM & $\Delta \mathrm{P}(\mathrm{mm} \mathrm{Hg})$ & $V \max \pm \mathrm{SEM}$ \\
\hline & $y r$ & & & $\%$ & & $M L / s$ \\
\hline 2 & 0.08 & TOF & female & $18.30 \pm 1.20$ & 92.00 & $1.67 \pm 0.07$ \\
\hline 42 & 2.00 & DORV & female & $13.90 \pm 0.90$ & 130.00 & $1.45 \pm 0.10$ \\
\hline 43 & 55.10 & DORV & male & $5.00 \pm 0.50$ & 63.00 & $1.57 \pm 0.25$ \\
\hline 23 & 1.00 & TOF & male & $14.00 \pm 0.80$ & 70.00 & $1.81 \pm 0.08$ \\
\hline 24 & 1.00 & TOF & female & $19.90 \pm 1.30$ & 85.00 & $2.25 \pm 0.11$ \\
\hline 33 & 1.55 & TOF & male & $15.00 \pm 0.70$ & 130.00 & $1.75 \pm 0.15$ \\
\hline 34 & 54.00 & IPS & female & $0.00 \pm 1.10$ & 115.00 & $1.24 \pm 0.10$ \\
\hline 36 & 10.50 & IPS & female & $3.00 \pm 0.20$ & 60.00 & nd \\
\hline 38 & 2.40 & TOF & male & $5.00 \pm 0.30$ & 67.00 & nd \\
\hline 39 & 2.90 & IPS & female & $4.00 \pm 0.15$ & 60.00 & $1.52 \pm 0.06$ \\
\hline 48 & 5.75 & TOF & female & $3.00 \pm 0.10$ & 73.00 & $1.61 \pm 0.08$ \\
\hline 50 & 3.40 & TOF & male & $2.00 \pm 0.10$ & 68.00 & nd \\
\hline 53 & 1.00 & TOF & male & $12.30 \pm 1.10$ & 80.00 & nd \\
\hline 55 & 17.20 & TOF & male & $7.70 \pm 0.80$ & 75.00 & nd \\
\hline 45 & 2.70 & DORV & male & $4.00 \pm 0.50$ & 60.00 & $1.26 \pm 0.08$ \\
\hline 58 & 1.10 & TOF & female & $9.50 \pm 1.10$ & nd & nd \\
\hline 59 & 2.50 & TOF & female & 0.00 & nd & nd \\
\hline 60 & 10.40 & TOF & female & $18.00 \pm 1.10$ & 60.00 & nd \\
\hline 61 & 7.80 & IPS & female & $0.00 \pm 0.00$ & 20.00 & nd \\
\hline 62 & 51.50 & TOF & male & $0.00 \pm 0.00$ & 110.00 & $1.22 \pm 0.11$ \\
\hline 63 & 0.95 & TOF & male & $11.40 \pm 1.20$ & 80.00 & nd \\
\hline 64 & 5.40 & IPS & male & $10.60 \pm 0.90$ & 65.00 & nd \\
\hline 49 & 1.20 & IPS & female & $11.00 \pm 1.00$ & 35.00 & nd \\
\hline 67 & 2.25 & TOF & male & $8.00 \pm 0.50$ & 65.00 & nd \\
\hline 68 & 10.10 & normal & female & $0.00 \pm 0.00$ & nd & $1.20 \pm 0.10$ \\
\hline 66 & 0.50 & DORV & female & $27.24 \pm 1.90$ & 15.00 & nd \\
\hline 47 & 0.10 & DORV & male & $6.00 \pm 0.40$ & 40.00 & nd \\
\hline
\end{tabular}

Hemodynamic (right ventricular pressure difference $\Delta \mathrm{P}$ ), biochemical (ALC-1 expression in \% fo MLC-1), and physiological data (Vmax in muscle length per second) of right ventricle of the heart from patients with congenital heart diseases. $(\mathrm{TOF}=$ Tetralogy of Fallot; DORV $=$ double outlet right ventricle; IPS = infundibular pulmonary stenosis). nd, not determined.

$(P+\mathrm{a})(v+\mathrm{b})=\left(P_{0}+\mathrm{a}\right) \mathrm{b}$

$v$ is the shortening velocity, $P$ is the force during isotonic contraction, $P_{0}$ is the maximal isometric steady state force, and a and b are constants. Maximal shortening velocity $\left(V_{\max }\right)$ was determined by extrapolation of Eq. 1 to zero-load.

Measurements of half-time of tension development $\left(t_{1 / 2}\right)$. Dissected fiber bundles were mounted isometrically in a $40 \mu \mathrm{l}$ quartz cuvette (Scientific Instruments, Heidelberg, Germany). Photolysis of caged ATP was achieved using a xenon flash lamp system (G. Rapp Optoelectronic, Hamburg, Germany). The lamp delivered UV light pulses with a duration of about $1 \mathrm{~ms}$ and was focused through a UG-11 filter. Force signals were displayed on a storage digital oscilloscope (HM 408) and analyzed with an IBM compatible PC. The experimental design was the same as elaborated previously (21). In short, the fibers were mounted isometrically and incubated in relaxation solution and subsequently in $\mathrm{Ca}^{2+}$-free rigor solution containing $100 \mathrm{mM} \mathrm{BDM}$ for $30 \mathrm{~min}$. In the presence of BDM, a "low-tension rigor" developed (21). Subsequently, the fibers were transferred in $\mathrm{Ca}^{2+}$-containing rigor solution ( $\mathrm{pCa} 4.5$ ) for $4 \mathrm{~min}$ and then in $\mathrm{Ca}^{2+}$ containing rigor plus $5 \mathrm{mM}$ caged-ATP for $5 \mathrm{~min}$. After registration of force development induced upon a light flash, the fiber was incubated in relaxation solution and subsequently in maximally contraction solution ( $\mathrm{pCa}$ 4.5). Temperature was always $21^{\circ} \mathrm{C}$.

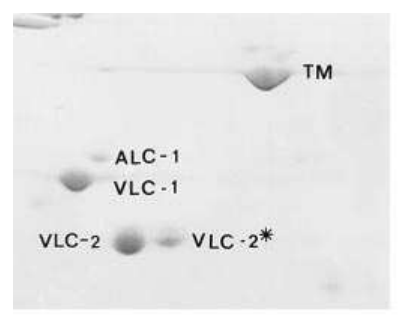

\section{Tetralogy of Fallot}

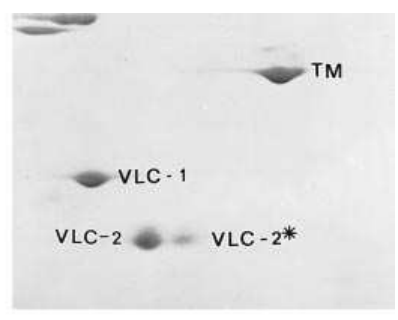

Normal Heart
Figure 1. Original photographs of MLC in the right ventricle of the human heart. MLC were analyzed by 2D-PAGE and stained with Coomassie-blue. (Left) Right ventricular tissue of a patient with Tetralogy of Fallot. (Right) Right ventricular tissue of a normal heart. ALC- 1 and VLC- 1 correspond to the atrial and ventricular essential MLC, respectively. VLC-2 and VLC-2* correspond to the ventricular regulatory MLC isoforms. $T M$, tropomyosin.

Statistical analysis. All statistical analysis were performed using commercially available statistic programs (Enzfitter, Epistat) on an IBM compatible PC. Values are means \pm SEM. Significance analysis was performed using the Student's t-test for unpaired values. Regression analysis was performed by the least-squares method.

\section{Results}

\section{Hemodynamic Data}

Pressure difference between right ventricle and pulmonary artery of all patient groups was between 15 and $120 \mathrm{mmHg}$ (Table I). The mean pressure difference of all patients investigated (24 patients) was $71.6 \pm 6.0 \mathrm{mmHg}$.

\section{Myosin Light Chain Analysis}

The MLC isoforms were analyzed according to their isoelectric point and molecular weight by 2D-PAGE. The ALC-1 revealed a higher molecular weight and was more acidic than the VLC-1. Fig. 1 shows two original gels of a multicellular demembranated right ventricular preparation of a normal patient (left) and a patient with TOF (right). Both fibers contained VLC-1, VLC-2, and VLC-2* but the TOF preparation contained in addition the ALC-1.

The mean ALC-1 expression of all patients with congenital heart disease (26 patients) was $8.5 \pm 1.4 \%$. However, not all patients contained ALC-1: 5 patients out of the 26 patients investigated in this study were virtually free of ALC-1 in the right ventricular infundibulum. Those patients who expressed ALC-1 revealed very different amounts ranging from 2 up to $27.2 \%$ ALC (expressed in \% of MLC-1, i.e., ALC-1 + VLC-1 = 100\%) (Table I).

The ratio between MLC- 1 and MLC- 2 was the same in all patient groups. In the normal heart, the MLC-1/MLC-2 ratio was $1.1 \pm 0.02$ (one patient). Taking all patients together (26 patients) we observed a MLC-1/MLC-2 ratio of $1.07 \pm 0.03 \%$.

We could not find any differences in the expression of ventricular MLC-2 isoforms (VLC-2 and VLC-2*) in the right ventricular fibers. In normal heart fibers, $70.6 \%$ of the MLC-2 forms was VLC-2. Taking all patients with congenital heart disease (26 patients) we observed a mean value of $70.3 \pm 1.3 \%$.

Both MLC-2 isoforms of all ventricular fiber preparations were completely dephosphorylated. The ALC-2 was never observed in our right ventricular fibers. 


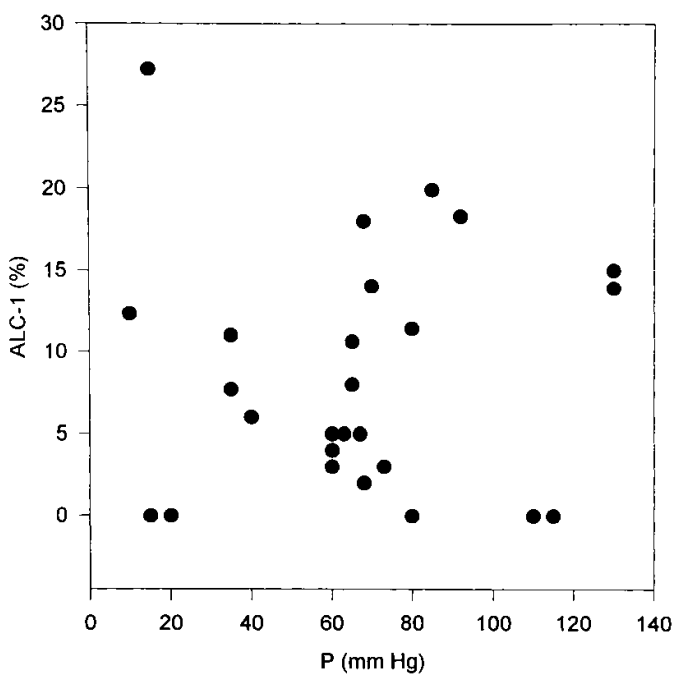

Figure 2. Correlation between $\Delta \mathrm{P}$ expressed in $\mathrm{mmHg}$ and ALC-1 expression (in \% of MLC-1 isoforms) of 27 patients with congenital heart diseases (TOF, DORV, IPS) and one normal heart.

There was no statistically significant difference between the pressure difference of patients with and without ALC-1: patients without ALC-1 revealed a pressure differerence of $81.6 \pm 25.5 \mathrm{mmHg}$ (three patients), the patients with ALC-1 (21 patients) had a pressure difference of $70.1 \pm 5.7 \%$. There was no correlation between pressure difference and ALC-1 expression (Fig. 2).

\section{Mechanical Analysis}

Isometric force production. Isometric steady-state tension $(\mathrm{mN})$ per cross-sectional area $\left(\mathrm{mm}^{2}\right)$ was obtained from skinned fi-

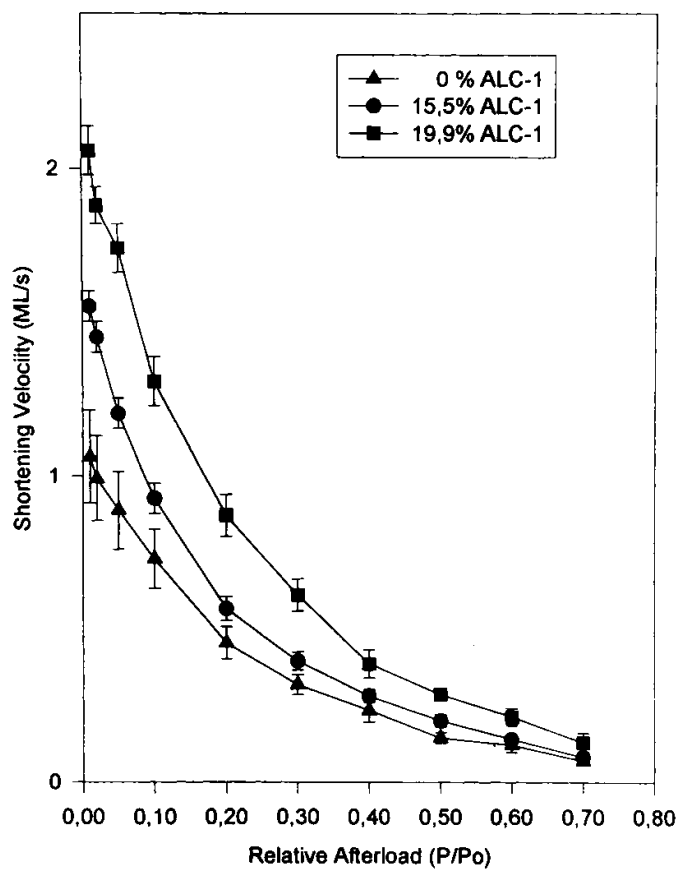

Figure 3. Force-velocity curves of skinned right ventricular fibers of patients with different amounts of ALC-1 in the ventricle (19.9, 15.5, and $0 \%$ ALC-1). $P_{0}$ is maximal isometric force, $P$ is the force during isotonic shortening. Shortening velocity is expressed in $M L / s$. Values are means of six different fibers each.

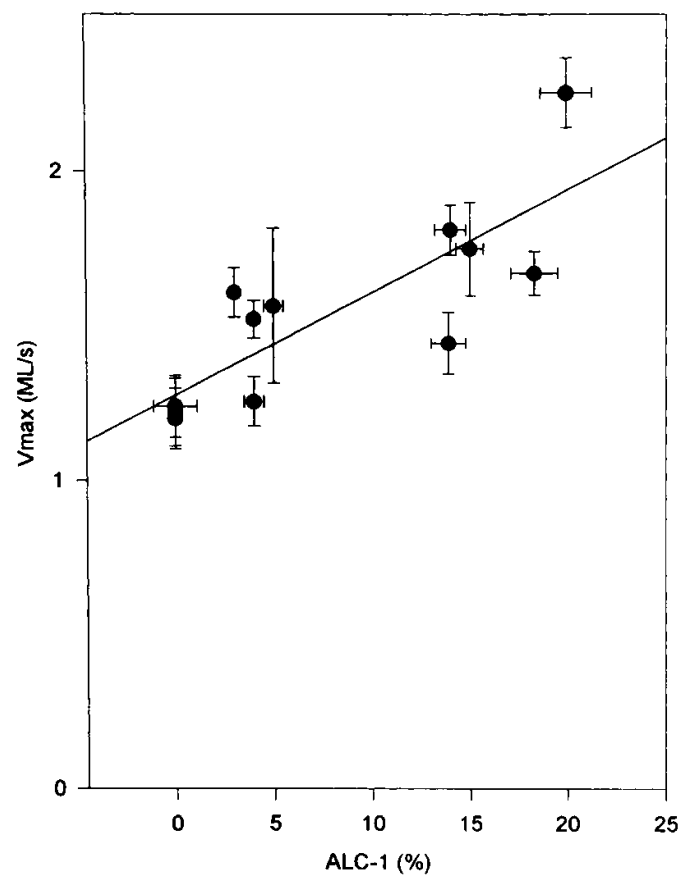

Figure 4. Correlation between ALC-1 expression (expressed in \% MLC-1 isoforms) and maximal shortening velocity $\left(V_{\max }\right)$ expressed in $\mathrm{ML} / \mathrm{s}$ of demembranated right ventricular fibers. Values are means \pm SEM. Analysis of $V_{\max }$ and ALC- 1 of six different fibers per patient.

bers maximally activated in contraction solution (pCa 4.5). 15 right ventricular fibers of three different patients with $0 \%$ ALC-1 (obtained from a normal heart, a patient with IPS, and a patient with TOF) was $352.6 \pm 46.6 \mathrm{mN} / \mathrm{mm}^{2}$. We observed significantly higher force productions per cross-sectional area with increasing ALC-1 expression: fibers with 0\% ALC-1 (six normal fibers), fibers containing 3-5\% ALC-1 and six different fibers of a TOF patient with $19.9 \%$ ALC-1 revealed $660 \pm 73 \mathrm{mN} / \mathrm{mm}^{2}(P<0.01)$ and $835.3 \pm 102 \mathrm{mN} / \mathrm{mm}^{2}(P<$ $0.01)$, respectively.

Force-velocity measurements. Force-velocity measurements could be performed with skinned right ventricular fiber preparations of 11 patients and one normal since in most cases tissue was not sufficient for combined biochemical and mechanical analysis. The force-velocity data of all fibers could well be fitted to a hyperbolic function. Fig. 3 shows representative curves of three patients with different amounts of ALC-1 expression. Please note from Fig. 3, that $V_{\max }$ of the human right ventricular fibers increased with increasing amounts of ALC-1 present.

Plotting the ALC- 1 expression versus the $V_{\max }$ values of all patients studied (means of 12 different patients and one normal heart, six fibers per patients), we observed a significant positive correlation between both parameters (Fig. 4). Evaluation of the relationship between ALC- 1 and $V_{\text {max }}$ by linear regression analysis revealed the equation:

$y=0.029 x+1.378$

This correlation was statistically significant $(P<0.01)$. Comparing $V_{\max }$ of patients with two different ALC-1 expression values, i.e., $0 \%$ ALC-1 and $19.9 \%$ ALC-1 we observed a statistically significant $(P<0.001)$ increase from $1.2 \pm 0.06 \mathrm{ML} / \mathrm{s}$ (normal heart, six fibers) to $2.26 \pm 0.1 \mathrm{ML} / \mathrm{s}$ (TOF, six fibers), respectively. 


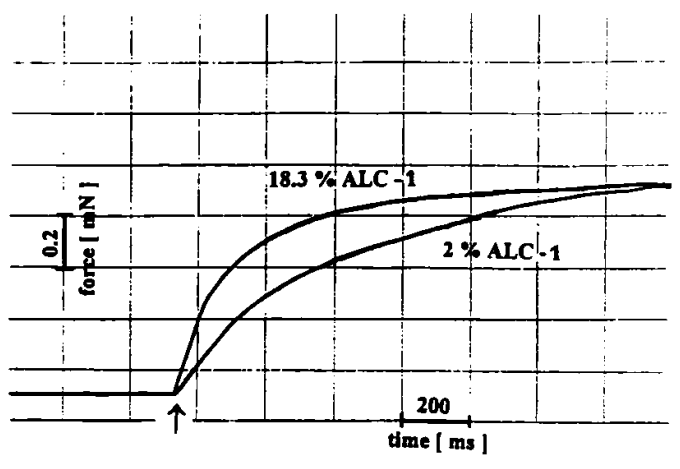

Figure 5. Original force registrations with high time-resolution from caged-ATP experiments on multicellular demembranated right ventricular fibers of two TOF patients with different amounts of ALC-1 (\% of MLC-1). All experiments were performed in low tension rigor achieved by incubation in rigor solution with BDM. Arrow indicates photolysis of caged-ATP. Please note that fibers with high ALC-1 developed faster isometric force than the fiber with low ALC-1.

In addition to $V_{\max }$, the curvature of the force-velocity relation changed with different ALC-1 expression levels. Increased ALC-1 levels was associated with a decrease of a $/ P_{0}$. Right ventricular fibers containing $0 \%$ ALC-1 revealed an a $/ P_{0}$ ratio of $0.21 \pm 0.02$ (normal heart, six fibers). Fibers with $19.9 \%$ ALC- 1 had an a/ $P_{0}$ of $0.15 \pm 0.02$ (TOF patients, six fibers).

There was no correlation between the age of the patients and $V_{\text {max }}$. Although the patients with $0 \%$ ALC- 1 were of different age, they had similar and not statistically different Vmax, namely 1.2 $\pm 0.06 \mathrm{ML} / \mathrm{s}$ (normal heart, $10 \mathrm{yr}$ ), $1.24 \pm 0.1$ $\mathrm{ML} / \mathrm{s}$ (IPS, $54 \mathrm{yr}$ ), and 1.22 $\pm 0.11 \mathrm{ML} / \mathrm{s}$ (TOF, $51.5 \mathrm{yr}$ ).

Half-time of force development $\left(t_{1 / 2}\right)$. Half-times of tension development of skinned human heart fibers were determined from the force-transient elicited upon photolytical release of ATP from caged ATP in low-tension rigor. Fig. 5 shows two superimposed original registrations of the tension transients of a fiber with $2 \%$ ALC-1 and a fiber with $18.4 \%$ ALC-1. Right ventricular fibers from a TOF patient with $2 \%$ ALC-1 revealed a significantly higher $t_{1 / 2}$ than a patient with TOF containing $18.4 \%$ ALC-1: $t_{1 / 2}$ was $0.252 \pm 0.04 \mathrm{~s}$ (six fibers) and $0.136 \pm 0.016 \mathrm{~s}$ ( six fibers) $(P<0.05)$, respectively (Fig. 5). This indicates a 1.85 -fold faster kinetics of tension development of myosin cross-bridges with high ALC-1 expression compared to those with low ALC-1.

Depletion of ADP by incubation of the fibers with apyrase (30 U/ml; Sigma) in rigor solution prior to the light-flash had no influence on kinetics of tension development: $t_{1 / 2}$ of an apyrase-treated TOF fiber with $2 \%$ ALC- 1 was $0.236 \pm 0.02 \mathrm{~s}$ (three fibers) (not shown).

\section{Discussion}

Expression of the embryonic (=atrial) MLC-1 (MLC-1emb or ALC-1) is developmentally regulated: It is expressed in striated muscle types during embryonic and early postnatal development and declines rapidly during postnatal development but it remains in the atrium during the whole life-span $(8,13,14)$. In the right ventricular infundibulum of patients with congenital heart disease, however the developmentally dependent decline of ALC-1 expression is much slower than in normal hearts (14). The relative persistence of the ALC-1 expression in patients with congenital heart disease could be explained by the high pressure overload caused by the right ventricular outflow obstruction and the development of right ventricular hypertrophy. In fact, a positive correlation between pressure overload in adult patients with valvular heart disease and ALC-1 expression in the left ventricle exists (18). Normalization of the hemodynamic state by valve replacement significantly reduced hypertrophy and ALC-1 expression (18). In young patients with congenital heart disease, however, at least two opposing factors exist regulating ALC-1 expression into different directions: decrease of ALC-1 expression with age and an upregulation of ALC-1 expression due to the high pressure overload. The existence of these counterbalancing factors which determine ALC-1 expression may be one of the causes of the missing correlation between pressure gradient and ALC-1 expression in patients with congenital heart diseases.

ALC-1 expression besides VLC-1, VLC-2, and VLC-2* in the human ventricle raises the question whether there is a compensatory down-regulation of the ventricular MLC isoforms. This could be answered by comparing the ratios between MLC-1 and MLC-2 which, according to the generally accepted myosin model ought to be 1.0 (i.e., each MHC monomer associated with one essential and one regulatory MLC) $(1,17)$. The MLC-1/MLC-2 ratio in the normal ventricle was indeed around one as predicted from the myosin model. This ratio did not change with additional ALC- 1 expression in patients with congenital heart diseases. Thus, we suspect that there is a compensatory downregulation of the VLC-1 expression in order to maintain the normal MLC-1/MLC-2 ratio.

Although many reports have demonstrated the expression of ALC-1 in the adult ventricle of patients with congenital or congestive heart diseases $(14,15,17,18)$, the functional consequences of essential myosin light chains remained unclear. Some work with skeletal muscle fibers suggest that essential myosin light chains play a role in shortening velocity $(24,25)$ but these studies are limited due to the coexistence of different myosin heavy chain isoforms in the fibers. In a recent study, which considered more carefully the myosin heavy chain variation in skeletal muscle fibers, maximal shortening velocity correlated negatively with the amount of MLC-3f (26). However, MLC-3 is an alternatively spliced isoform of the MLC-1 which lacks the first $41 \mathrm{NH}_{2}$-terminal amino acids and which does not exist in the heart $(27,28)$.

In this study we analyzed the role of essential MLC on cross-bridge cycling kinetics of the human heart. We measured maximal shortening velocity $\left(V_{\max }\right)$ and half-time of tension development $\left(t_{1 / 2}\right)$ of demembranated multicellular fibers (skinned fibers) prepared from the right ventricular infundibulum obtained from patients with congenital heart defects (TOF, DORV, or IPS). To guarantee selective analysis of myosin function and to exclude the influence of changes of regulatory proteins, we investigated $V_{\max }$ and $t_{1 / 2}$ at maximal $\mathrm{Ca}^{2+}$ activation (pCa 4.5). Different expression of $\mathrm{MHC}$ in the normal and hypertrophied infundibulum could be excluded since only the $\beta$-MHC was found to be expressed (14).

The important observations in this paper are that ALC-1 expression was associated with increased isometric tension, $V_{\max }$, and velocity of tension development (decrease of $t_{1 / 2}$ ). Since we have chosen our experimental conditions such that the behavior of the myosin cross-bridge is considered and since only the essential MLC isoforms changed we feel justified to causally relate myosin cross-bridge kinetics and contractility to essential MLC expression. 
Increased isometric tension per cross-section is interesting since it allows some speculations concerning the characteristics of myosin cross-bridges: steady-state isometric force $\mathrm{F}$ of a muscle fiber can be described by the equation:

$\mathrm{F}=\mathrm{F}^{\prime}$ ntot $\mathrm{f}_{\text {app }} /\left(\mathrm{f}_{\text {app }}+\mathrm{g}_{\text {app }}\right)$

where $\mathrm{F}^{\prime}$ is the force generation per cross-bridge, ntot is the total amount of cycling cross-bridges per half-sarcomere, $\mathrm{f}_{\mathrm{app}}$ is the rate-constant for transition from nonforce into force-generating state (attachment rate), and $g_{a p p}$ is the rate-constant for the transition of cross-bridges from force into nonforce generating states (detachment rate) (31). It seems to be unlikely that ntot changed since we activated our fibers at maximal $\mathrm{Ca}^{2+}$ concentrations ( $\mathrm{pCa} 4.5$ ). Thus, both $\mathrm{F}^{\prime}$ as well as the crossbridge-cycling kinetics ( $f_{\text {app }}$ and/or $g_{\text {app }}$ ) may change with ALC-1 expression.

According to the cross-bridge hypothesis of A.F Huxley 1957 (38), $V_{\max }$ depends on the detachment rate constant of negatively strained cross-bridges and, therefore provides information of the cross-bridge cycling kinetics. Normal ventricular fibers revealed a $V_{\max }$ of $1.2 \mathrm{~mL} / \mathrm{s}$ by extrapolation of the forcevelocity curve to zero-load. Calculation of $V_{\max }$ from the ALC$1-V_{\max }$ regression line revealed a normal value of about 1.4 $\mathrm{mL} / \mathrm{s}$ (fibers with $0 \%$ ALC-1 as determined from the intercept with the $\mathrm{Y}$ axis). These normal $V_{\max }$ values of human ventricle are in agreement with our previous determination using the slack-test technique (44). We found a significant positive correlation between ALC-1 expression and $V_{\max }$. From two extreme points of the ALC- $1-V_{\max }$ correlation ( 0 and $19.9 \%$ ALC-1) we calculated a 1.85 -fold increase of $V_{\max }$. This result demonstrates the strong influence of essential MLC on crossbridge cycling kinetics in the heart: myosin cross-bridges with the composition $\beta$-MHC/ALC-1/VLC-1/VLC-2/VLC-2* revealed a higher detachment rate than myosin cross-bridges with the compostition $\beta$-MHC/VLC-1/VLC-2/VLC-2*.

An additional factor which might influence $V_{\max }$ is the presence of "internal loads" due to different amounts of connective tissue. Fibrosis of cardiac tissue is a common observation in cardiac hypertrophy and during development (39). Theoretically, frictional forces should decrease shortening velocity and the curvature of the force-velocity relationship, hence increasing a $/ P_{0}$. However, we observed an increased $V_{\max }$ and decreased a $/ P_{0}$ in the hypertrophied hearts of patients with congenital heart disease. Furthermore, there was no correlation between age and Vmax which has to be predicted if the degree of fibrosis would have determined Vmax: Vmax of all ventricular fibers with no ALC-1 (three patients) were in the same range despite the very different ages of the patients (8-54 yr). We cannot exclude the possibility, however, that we underestimated the positive influence of ALC-1 expression on cardiac contractility since high internal loads in the hypertrophied hearts may have balanced ALC-1 effects.

Transition of cross-bridges from non-force into force generating states measured as half-time of tension development (expressed as $t_{1 / 2}$ ) during maximal $\mathrm{Ca}^{2+}$ activation of ventricular fibers was lower in the presence of high compared to fibers with low amounts of ALC-1. We consider the thin filament regulatory system to be fully activated under our experimental conditions, hence $t_{1 / 2}$ reflects the transition from non-force into force-generating states. When analyzed according to a twostate model (cf. 31,38$), t_{1 / 2}$ equals $\left(f_{\text {app }}+g_{\text {app }}\right)$. We cannot decide which kinetic parameter increased by additional expres- sion of ALC-1 ( $f_{\text {app }}$ or $g_{\text {app }}$ or both). Due to its effect on $V_{\max }$ we can, however, speculate that it is at least an increased detachment rate which is responsible for the ALC-1-induced increased velocity of tension development.

Increasing the phosphorylation level of the regulatory MLC of the heart catalyzed by a $\mathrm{Ca}^{2+}$ calmodulin-dependent MLC kinase increased the $\mathrm{Ca}^{2+}$ sensitivity of the isometric tension production in the animal (19) and human (20) heart. The increased $\mathrm{Ca}^{2+}$ sensitivity could be explained at least partially by an increased attachment-rate constant of the myosin crossbridge upon MLC-2 phosphorylation (21). Since the regulatory light chains were completely dephosphorylated, we can rule out an influence of different phosphorylated states of the fibers on isometric tension, $V_{\max }$, and $t_{1 / 2}$. The fibers were completely dephosphorylated because we used $\mathrm{Ca}^{2+}$-free conditions for preparation. Under this condition, the myosin light chain kinase which is $\mathrm{Ca}^{2+}$ calmodulin dependent, is inactive while the light chain phosphatase remains active leading to a dephosphorylation (20).

ADP can bind to rigor cross-bridges and affect the detachment rate (32). However, depletion of the fibers from ADP by apyrase-treatment had no influence on $\mathrm{t}_{1 / 2}$ of skinned ventricular fibers. The molecular mechanism explaining the effect of essential MLC in the heart may reside in the mode of interaction between MLC-1 and actin. It has been demonstrated that the amino-terminal domain of MLC-1 isoforms bind to the carboxyl-terminal domain of actin $(40,41)$. This interaction could be of functional importance since inhibition of this interaction using synthetic peptides increased force production and shortening velocity of human heart fibers (22). We proposed that MLC-1-actin interaction imposes a kind of "molecular load" on the myosin cross-bridge. Relieving this load increases contractility. Interestingly, the primary structure of the most amino terminus of the ALC- 1 and VLC-1 are different (10), suggesting different binding strength between ALC-1, VLC-1, and actin. In our hands, binding of ALC-1 to actin should be weaker than binding of VLC-1 thus decreasing the "molecular load" imposed on the cross-bridge. This would, in analogy to weakening MLC-1-actin interaction by peptides, explain the increased force production and accelerated cross-bridge cycling kinetics associated with ALC-1 expression in the human ventricle.

Regulation of cardiac contractility by expression of different essential MLC isoforms in the human ventricle is different from the mode of regulation in the rodent heart. It is now well established that rodents change their MHC rather than MLC expression due to hormonal, developmental, or hemodynamic changes or as response to different environmental demands (43). In these species $\alpha$-MHC expression increased shortening velocity, energy consumption, and oxygen consumption while an increased expression of the $\beta$-MHC decreased these parameters (43).

In summary, we presented evidence for an upregulation of cross-bridge cycling kinetics and contractility of the hypertrophied human ventricle caused by the expression of the ALC-1. The human ventricle, therefore seems to regulate its contractility by changing MLC rather than MHC isoforms which is common for rodents.

\section{Acknowledgments}

We would like to thank S. Hille for excellent technical assistance. Supported by DFG Mo 362/15-1. 


\section{References}

1. Lowey, S., D. Risby. 1971. Light chains from fast and slow muscle myosins. Nature (Lond.). 234:81-85.

2. Leinwand, L.A., R.E.K. Fournier, B. Nadal-Ginard, and T.B. Shows. 1983. Isolation and characterization of human myosin heavy chain genes Proc. Natl. Acad. Sci. USA. 80:3716-3720.

3. Saez, L.J., K.M. Gionola, E.M. McNally, R. Feghali, R. Eddy, T.B. Shows, and L.A. Leinwand. 1987. Human cardiac myosin heavy chain genes and their linkage in the genome. Nucleic Acids Res. 15:5443-5359.

4. Mahdavi, V., A.P. Chambers, and B. Nadal-Ginard. 1984. Cardiac alphaand beta-MHC genes are organized in tandem. Proc. Natl. Acad. Sci. USA. 81: 2626-2630.

5. Delcayre, C., and B. Swynghedauw. 1975. A comparative study of heart myosin ATPase and light subunits from different species. Pflügers Arch. 355: 39-47.

6. Weeds, A.G., and B. Pope. 1971. Chemical studies on light chains from cardiac and skeletal muscle myosins. Nature (Lond.). 234:85-88.

7. Rayment, I., W.R. Rypniewski, K. Schmidt-Bäase, R. Smith, D.R. Tomchick, M.M. Benning, D.A. Winkelmann, G. Wesenberg, and H.M. Holden 1993. Three-dimensional structure of myosin subfragment-1: a molecular motor. Science (Wash. DC). 261:50-58.

8. Price, K.M., W.A. Littler, and P. Cummins. 1980. Human atrial and ventricular myosin light chains subunits in the adult and during development. Biochem. J. 191:571-580.

9. Morano, I., M. Wankerl, M. Böhm, E. Erdmann, and J.C. Rüegg. 1989. Myosin P-light chain isoenzymes in the human heart: evidence for diphosphorylation of the atrial P-LC form. Basic Res. Cardiol. 84:298-305.

10. Kurabayashi, M., I. Komuro, H. Tsuchimochi, F. Takaku, and Y. Yazaki. 1988. Molecular cloning and characterization of human atrial and ventricular myosin alkali light chain cDNA clones. J. Biol. Chem. 263:13930-13936.

11. Zimmermann, K., S. Kautz, G. Hajdu, C. Winter, R.G. Whalen, and A. Starzinski-Powitz. 1990. Heterogenic mRNAs with an identical protein-coding region of the human embryonic myosin alkali light chain in skeletal muscle cells. J. Mol. Biol. 211:505-513.

12. Catala, F., R. Wanner, P. Barton, A. Cohen, W. Wright, and M. Buckingham. 1995. A skeletal muscle-specific enhancer regulated by factors binding to $\mathrm{E}$ and $\mathrm{CArG}$ boxes is present in the promotor of the mouse myosin light chain 1A gene. Mol. Cell. Biol. 15:4585-4596.

13. Barton, P., and M.E. Buckingham. 1992. The myosin alkali light chain proteins and their genes. Biochem. J. 231:249-261.

14. Auckland, L.M., S.J. Lambert, and P. Cummins. 1986. Cardiac myosin light and heavy chain isotypes in Tetralogy of Fallot. Cardiovasc. Res. 20:828863.

15. Cummins, P., and S.J. Lambert. 1986. Myosin transitions in the bovine and human heart. A developmental and anatomical study of heavy and light subunits in the atrium and ventricle. Circ. Res. 58:846-858.

16. Fallot, A. 1888. Contribution a l'anatomie pathologique de la maladie bleue (cyanose cardiac) Marseille Med. 25:418-420.

17. Schaub, M.C., C.R. Tuchschmid, T. Srihari, and H.O. Hirzel. 1984. Myosin isoenzymes in human hypertrophic hearts. Shift of atrial myosin heavy chains and in ventricular light chains. Eur. Heart J. 5:(Suppl. F) 85-93.

18. Sütsch, G., U.T. Brunner, C. Von Schulthess, H.O. Hirzel, O.M. Hess, M. Turina, H.P. Krayemnbuehl, and M.C. Schaub. 1992. Hemodynamic performance and myosin light chain-1 expression in the hypertrophied left ventricle in aortic valve disease before and after valve replacement. Circ. Res. 70:10351043.

19. Morano, I., F. Hofmann, M. Zimmer, and J.C. Rüegg. 1986. The influence of P-light chain phosphorylation by myosin light chain kinase on the calcium sensitivity of chemically skinned heart fibers. FEBS Lett. 189:221-224.

20. Morano, I., C. Bächle-Stolz, H. Katus, and J.C. Rüegg. 1988. Increased calcium sensitivity of chemically skinned human atria by myosin light chain kinase. Basic Res. Cardiol. 83:350-359.

21. Morano, I., A. Österman, and A. Arner. 1995. Rate of active tension development from rigor in skinned atrial and ventricular cardiac fibers from swine following photolytic release of ATP from caged ATP. Acta Physiol. Scand. 154:
343-353

22. Morano, I., O. Ritter, A. Bonz, T. Timek, C.F. Vahl, and G. Michel. 1995. Myosin light chain-actin interaction regulates cardiac contractility. Circ. Res. 76:720-725

23. Morano, I., K. Hädicke, M. Böhm, and E. Erdmann. 1993. Atrial myosin light chain 1 expression in the human ventricle correlates with increased calcium sensitivity of skinned fibers. J. Mol. Cell Cardiol. 25(II): 131a (Abstr.).

24. Eddinger, T.J., and R.L. Moss. 1987. Mechanical properties of skinned single fibers of identified types from rat diaphragm. Am. J. Physiol. 253:C210 218.

25. Sweeny, H.L., M.J. Kushmerick, K. Mabuchi, F.A. Sreter, and J. Gergely. 1988. Myosin alkali light chain and heavy chain variations correlate with altered shortening velocity of isolated skeletal muscle fibers. J. Biol. Chem. 263:9034-9039.

26. Bottinelli, R., R. Betto, S. Schiaffino, and C. Reggiani. 1994. Unloaded shortening velocity and myosin heavy chain and alkali light chain isoform composition in rat skeletal muscle fibers. J. Physiol. 478:341-349.

27. Frank, G., and A.G. Weeds. 1974. The amino-acid sequence of the alkali light chains of rabbit skeletal muscle myosin. Eur. J. Biochem. 44:317-334.

28. Periasamy, M., E.E. Strehler, L.I. Garfinkel, R.M. Gubits, N. RuizOpazo, and B. Nadal-Ginard. 1984. Fast skeletal muscle myosin light chains 1 and 3 are produced from a single gene by a combined process of differential RNA transcription and splicing. J. Biol. Chem. 259:13595-13604.

29. Kawai, M., Y. Saeki, and Y. Zhao. 1993. Cross-bridge scheme and the kinetic constants of elementary steps deduced from chemically skinned papillary and trabecular muscles of the ferret. Circ. Res. 73:35-50.

30. Eisenberg, E., and T.L. Hill. 1985. Muscle contraction and free energy transduction in biological systems. Science (Wash. DC). 227:999-1006.

31. Brenner, B. 1986. Effect of $\mathrm{Ca}^{2+}$ on cross-bridge turnover kinetics in skinned single rabbit psoas fibers: implications for regulation of muscle contraction. Proc. Natl. Acad. Sci. USA. 85:3265-3269.

32. Dantzig, J.A., Y.E. Goldman, N.C. Millar, J. Lacktis, and E. Homsher. 1992. Reversal of the cross-bridge force-generating transition by photogeneration of phosphate in rabbit psoas muscle fibers. J. Physiol. 451:247-278.

33. Siemankowski, R.F., M.O. Wiseman, and H.D. White. 1985. ADP dissociation from actomyosin subfragment 1 is sufficiently slow to limit the unloaded shortening velocity in vertebrate muscle. Proc. Natl. Acad. Sci. USA. 82:658662 .

34. McCray, J.A., L. Herebette, T. Kihara, and D.R. Trentham. 1980. A new approach to time-resolved studies of ATP-requiring biological systems: laser-flash photolysis of caged ATP. Proc. Natl. Acad. Sci. USA. 77:7237-7241.

35. Martin, H., and R.G. Barsotti. 1994. Activation of skinned trabeculae of the guinea pig induced by laser photolyisis of caged ATP. Biophys. J. 67:19331941.

36. Fabiato, A., and F. Fabiato. 1979. Calculator programs for computing the compositions of the solutions containing metals and ligands used for experiments in skinned muscle cells. J. Physiol. (Paris). 75:463-505.

37. Hill, A.V. 1938. The heat of shortening and the dynamic constants of shortening. Proc. R. Soc. Lond. (Biol.). 126:136-159.

38. Huxley, A.F. 1957. Muscle structure and theories of contraction. Prog. Biophys. Biophys. Chem. 7:255-318.

39. Weber, K.T. 1992. Cardiac interstitium: extracellular space of the myocardium. In The Heart and Cardiovascular System. Second edition. Fozzard H.A. et al., editors. Raven Press, New York. 1465-1480.

40. Trayer, I.P., H.P. Trayer, and B.A. Levine. 1987. Evidence that the Nterminal region of the $\mathrm{A} 1$ light chain of myosin interacts directly with the $\mathrm{C}$-terminal region of actin. Eur. J. Biochem. 164:259-266.

41. Sutoh, K. 1982. Identification of myosin binding sites on the actin sequence. Biochemistry 21:3654-3661.

42. Sweeney, H.L. 1995. Function of the N-terminus of the myosin essential light chain of vertebrate striated muscle. Biophys. J. 68:112-119.

43. Swynghedauw, B. 1986. Developmental and functional adaptation of contractile proteins in cardiac and skeletal muscles. Physiol. Rev. 66:710-771.

44. Morano, I., H. Arndt, C. Gärtner, and J.C. Rüegg. 1988. Skinned fibers of human atrium and ventricle: myosin isoenzymes and contractility. Circ. Res. 62:632-639. 